\title{
Creutzfeldt-Jakob Disease with Unusual Visual Hallucination : A Case Report
}

\author{
Si Hyun Rho, Hyo Joon Kim, Min Park \\ Department of Neurosurgery, Presbyterian Medical Center, Jeonju, Korea
}

Received: September 12, 2021

Accepted: October 5, 2021

Corresponding Author:

Hyo Joon Kim, MD, PhD

Department of Neurosurgery,

Presbyterian Medical Center, 365,

Seowon-ro, Wansan-gu, Jeonju

54987, Korea

Tel: +82-63-230-1420

Fax: +82-63-230-1426

Email:hj-kim@hanmail.net
Clinical features seen in patients with sporadic Creutzfeldt-Jakob disease (sCJD) may be diverse symptoms. Due to diverse clinical features, it may be necessary to differentiate from cerebrovascular disease or psychotic symptoms during initial evaluation. In this case, we discuss the clinical case of a 57-year-old female patient with multiple neurological symptoms. The patient showed clinical features of alice in Wonderland syndrome during evaluation and conservative care, and was diagnosed with sCJD. In this regard, it is considered that evaluation and management are required along with recognition of the possibility of non-specific neurological symptoms such as AIWS in sCJD patients in the future.

Keywords: Creutzfeldt-Jakob disease; Alice in Wonderland syndrome; Neuropsychotic symptoms

\section{INTRODUCTION}

Initially described in 1921, Creutzfeldt-Jakob disease (CJD) is a rare, transmissible prion disease ${ }^{1)}$. There are four types of CJD known. Sporadic, familial, iatrogenic and variant, of which sporadic Creutzfeldt-Jakob disease (sCJD) is the most common, and sCJD has characteristic clinical and diagnostic features ${ }^{2-4)}$. It is a rapidly progressive, deadly infectious disease that usually results in death within a year of onset ${ }^{3,4)}$.

The disease is thought to be caused by an abnormal isoform of a cellular glycoprotein known as prion protein, and is found in about 1 in 1 million people ${ }^{4-6)}$. Sporadic Creutzfeldt-Jakob disease, like other prion diseases, is classified as a transmissible spongiform encephalopathy and occurs as a sporadic disease without a recognizable transmission pattern in approximately $85 \%$ of patients ${ }^{6}$. Current criteria for diagnosis include a distinct phenotype, periodic sharp and slow-wave complexes at electroencephalography (EEG), and a positive 14-3-3-protein assay in the cerebrospinal fluid (CSF). But the definitive diagnostic method for SCJD is neuropathologic or immunodiagnostic testing of brain tissue through biopsy or autopsy $^{5-7)}$.

Neuropsychiatric symptoms are relatively common in the early stage of variant Creutzfeldt-Jakob disease (vCJD), but psychiatric manifestations are reported to be rare in the clinical features of $\operatorname{sCJD}^{8,9)}$.

In this case report, we would like to report a case in which a patient with unusual visual hallucination was diagnosed with CJD.

\section{CASE REPORT}

A 57-year-old female patient visited the emergency room with seizure, visual Hallucination, cognitive decline, left limb weakness, and gait disturbance that occurred 2 days before admission.

She had a history of being admitted to a psychiatric hospital for

Copyright (C) 2021 The Korean Neurointensive Care Society

This is an Open Access article distributed under the terms of the Creative Commons Attribution Non-Commercial License (http://creativecommons.org/licenses/by-nc/4.0/) which permits unrestricted non-commercial use, distribution, and reproduction in any medium, provided the original work is properly cited. 
heavy alcohol use. The patient showed signs of recovery in consciousness and limb weakness during treatment in the intensive care unit for several days, but disorientation of places and people and hallucinations and illusions continued intermittently. In particular, she showed a continuous virtual conversation with family members who did not reside next to her, and When the medical staff asked about this, she mistakenly thought it was her son and continued talking. Sometimes, when the medical staff talked to her during the examination, she was excessively afraid, saying that she looked like a blank face when seeing the medical staff and she also was aggressive in accusing the medical staff of appearing too big a monster.

We performed brain magnetic resonance imaging (MRI) after admission, on the diffusion weighted and T2 FLAIR image, high signal intensity lesions were observed in the medial frontal cortex, right hippocampus, right insular cortex, right temporal cortex, and right thalamus including the right cingulate gyrus. (Figs. 1, 2) For further evaluation, cerebrospinal fluid (CSF) analysis was performed through lumbar, we checked positive findings of 14-3-3 protein test.

We were finally diagnosed with sCJD, and after about 2 weeks of treatment in the neurosurgery intensive care unit (NCU), the patient's symptoms improved. After fully explaining to the patient's family that there is no treatment for the disease and the poor prognosis, she was discharged on the 13th day of hostital day. We planned follow-up through outpatient treatment.

\section{DISCUSSION}

Various psychiatric symptoms such as sleep disturbance, psy- chosis, depressive, and behavioral dyscontrol anxiety are rarely reported in $\mathrm{SCJD}^{10,11)}$. Among them, there was a case that reported visual hallucination as in this case ${ }^{12,13)}$

The mechanism by which these symptoms occur in SCJD is not known, but it is thought to be related to the limbic system. Limbic system damage was also observed in some cases we investigated, and in this case, limbic system damage is also suspected. In some cases, medication was needed, but in most cases it improved $^{12-14)}$.

\section{CONCLUSIONS}

Although rare in SCJD, visual hallucination may also be present. Visual hallucination is expected to have a good prognosis.

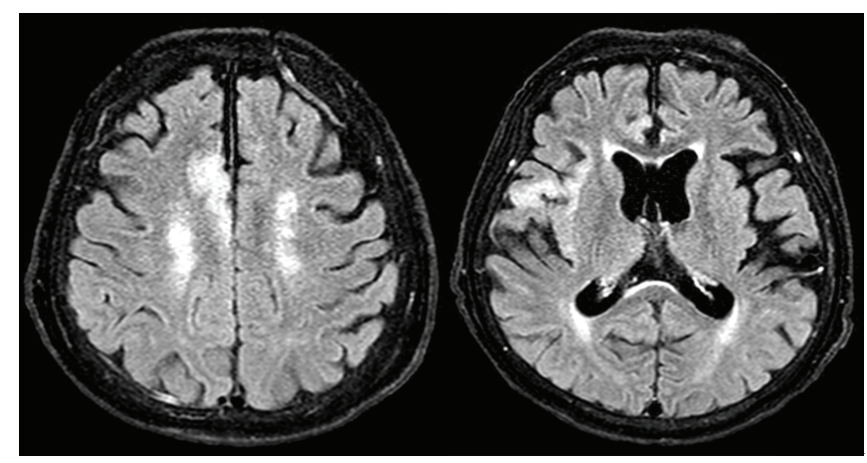

Fig. 2. MRI T2 FLAIR image. High signal intensity lesions were observed in the medial frontal cortex, right hippocampus, right insular cortex, right temporal cortex, and right thalamus including the right cingulate gyrus.

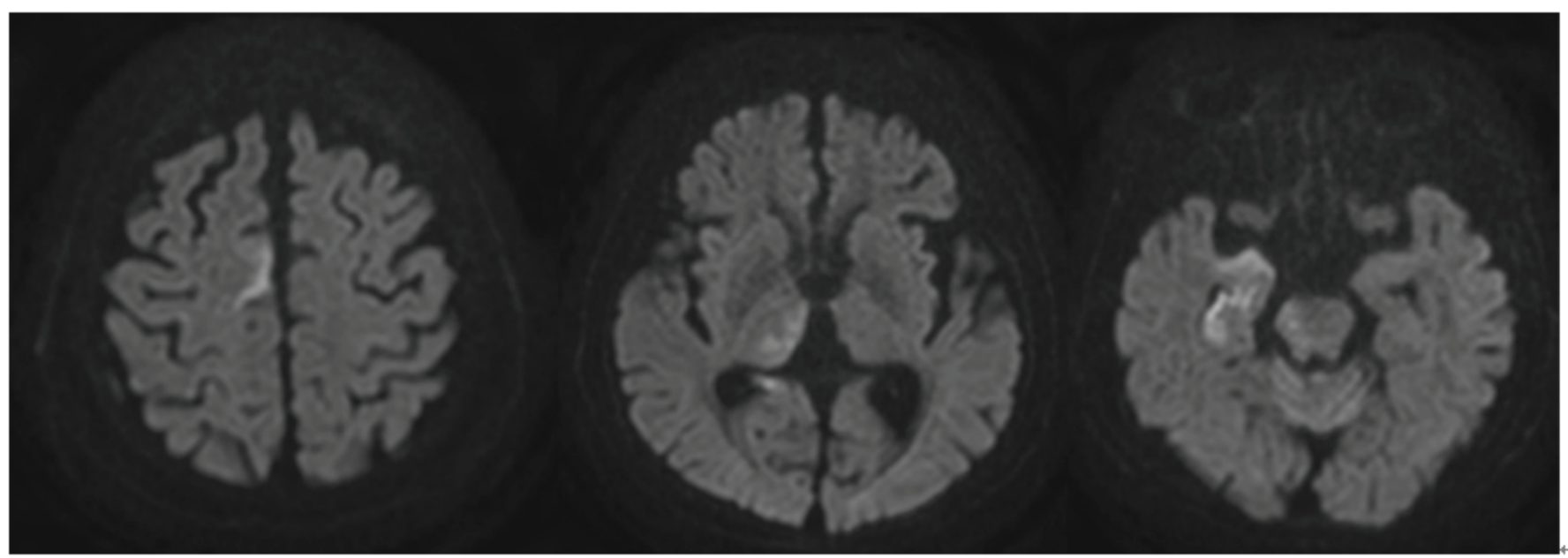

Fig. 1. MRI diffusion weighted image. High signal intensity lesions were observed in the medial frontal cortex, right hippocampus, right insular cortex, right temporal cortex, and right thalamus including the right cingulate gyrus. 


\section{NOTES}

\section{Conflict of interest}

No potential conflict of interest relevant to this article was reported.

\section{REFERENCES}

1. Pearce JM. Jakob-Creutzfeldt disease. Eur Neurol 2004; 52:129-31.

2. Sikorska B, Knight R, Ironside JW, Liverski PP. Cretzfeldt-Jakob disease. Adv Exp Med Biol 2012;724:76-90.

3. Uttley L, Carroll C, Wong R, Hilton DA, Stevenson M. Creutzfeldt-Jakob disease: a systematic review of global incidence, prevalence, infectivity, and incubation. Lanjcet Infect Dis 2020;20:e2-e10.

4. Zerr I, Parchi P. Sporadic Creutzfeldt-Jakob disease. Handb Clin Neurol 2018; 153:155-174.

5. Manix M, Kalakoti P, Henry M, Thakur J, Menger R, Guthikonda B, et al. Creutzfeldt-Jakob disease: updated diagnostic criteria, treatment algorithm, and the utility of brain biopsy. Neurosurg Focus 2015;39:E2.

6. Appleby BS, Appleby KK, Crain BJ, Onyike CU, Wallin MT, Rabins PV. Characteristics of established and proposed sporadic Creutzfeldt-Jakob disease variants. Arch Neurol 2009;66: 208-15.

7. McGuire LI, Peden AH, Orrú CD, Wilham JM, Appleford NE,
Mallinson G, et al. Real time quaking-induced conversion analysis of cerebrospinal fluid in sporadic Creutzfeldt-Jakob disease. Ann Neurol 2012;72:278-285.

8. Brown P, Cathala F, Castaigne P, Gajdusek DC. Creutzfeldt-Jakob disease: clinical analysis of a consecutive series of 230 neuropathologically verified cases. Ann Neurol 1986;20:597-602.

9. Will R, Matthews W, Smith P, Hudson C. A retrospective study of Creutzfeldt-Jakob disease in England and Wales 1970-1979.J Neurol Neurosurg Psychiatry 1986;49:749-755.

10. Wall CA, Rummans TA, Aksamit AJ, Krahn LE, Pankratz VS. Psychiatric Manifestations of Creutzfeldt-Jakob Disease: A 25Year Analysis. J Neuropsychiatry Clin Neurosci 2005; 17:48995.

11. Yen CF, Lin RT, Liu CK, Lee PW, Chen CC, Chang YP. The psychiatric manifestation of Creutzfeldt-Jakob disease. Kaohsiung J Med Sci 1997;13:263-7.

12. Abudy A, Wetzler AJ, Zohar J. The different faces of Creutzfeldt-Jacob disease CJD in psychiatry. Gen Hosp Psychiatry 2014;36:245-8.

13. Li X, Lapid MI, Burton MC, Josephs KA. Psychoses as the presenting manifestation of Creutzfeldt-Jakob disease in an elderly male. Gen Hosp Psychiatry 2011;33:302.e7-9.

14. Baiardi S, Cappellari S, Stella AB, Perchi P. Unusual Clinical Presentations Challenging the Early Clinical Diagnosis of Creutzfeldt-Jakob Disease. J Alzheimers Dis 2018;64:10511065. 